\title{
A Criança Hiperativa: Uma Visão da Abordagem Gestáltica ${ }^{1}$
}

\author{
Sheila Antony ${ }^{2}$ \\ Jorge Ponciano Ribeiro \\ Universidade de Brasília
}

\begin{abstract}
RESUMO - A pesquisa objetivou investigar o funcionamento psicológico da criança hiperativa em base a teoria do ciclo do contato da abordagem gestáltica, proposta por Ribeiro (1997). O Transtorno de Déficit de Atenção/Hiperatividade (TDAH) caracteriza-se por distúrbios motores, perceptivos, emocionais e comportamentais. Segundo os critérios diagnósticos do DSMIV (1994), esse transtorno reúne 18 sintomas básicos de desatenção, hiperatividade e impulsividade. A pesquisa adotou uma abordagem qualitativa. A amostra foi composta por 20 sujeitos: cinco casais, cinco professoras e cinco crianças entre oito e 11 anos de idade. Utilizaram-se a entrevista aberta e o Teste de Apercepção Infantil com figuras de animais (CAT-A), como instrumentos de coleta de dados. Concluímos que a criança hiperativa apresenta processos psicológicos específicos que formam a base de sua personalidade. A hiperatividade é a característica que define o transtorno. Não há propriamente um déficit de atenção. Propomos, portanto, uma terminologia diferente: Transtorno de Hiperatividade/Atenção.
\end{abstract}

Palavras-chave: hiperatividade; desatenção; TDAH; gestalt; ciclo do contato.

\section{Hyperactive Child: A Gestaltic View}

\begin{abstract}
The study investigated the psychological functioning of the hyperactive child according to Contact Cycle Theory of Gestalt Approach, proposed by Ribeiro (1997). Attention Deficit/Hyperactivity Disorder (ADHD) is characterized by motor, perceptual, emotional and behavioral disturbances. According to DSM-IV (1994), the disorder comprises 18 basic symptoms of inattention, hyperactivity and impulsiveness. The research adopted a qualitative approach. The sample was composed by 20 subjects: five couples, five teachers and five children from eight to 11 years old. Non-structured interviews and children's apperception test using animal figures (CAT-A) were applied as instruments to collect data. We concluded that hyperactive child displays specific psychological processes forming the base of his personality, hyperactivity is the characteristic that defines the disorder, and that there is no attention deficit properly. Thus, we propose a different terminology: Hyperactivity/Attention Disorder.
\end{abstract}

Key words: hyperactivity; inattention; ADHD; gestalt; contact cycle.

Atualmente, o Transtorno de Déficit de Atenção/Hiperatividade (TDAH) constitui uma complexa desordem comportamental que leva a criança a graus variáveis de comprometimento na vida social, emocional, escolar e familiar. Esse transtorno caracteriza-se por distúrbios motores, perceptivos, cognitivos e comportamentais, expressando dificuldades globais do desenvolvimento infantil.

O TDAH tem sido objeto de estudo de inúmeras pesquisas que visam fundamentalmente aprimorar os critérios diagnósticos e conhecer sua etiologia. Ao longo do tempo muitos estudos têm sido orientados para encontrar uma causa biológica específica que explique o TDAH. Evidências conclusivas de lesão ou disfunção neurofisiológica são pouco substanciais e continuam incertas. Conforme dito por Debroitner e Hart (1997):

Aqueles que ainda hoje investem na idéia de que o TDAH é uma doença (invisível) do cérebro estão buscando uma explicação simples para um distúrbio que é complexo e multidimensional. Acreditamos que a nossa obsessão nacional pela genética

1 Trabalho baseado na Dissertação de Mestrado da primeira autora sob a orientação do segundo autor.

2 Endereço: SQN 202 Bloco D ap. 201, Brasília, DF, Brasil 70832-040. E-mail: sheilaantony@ conectanet.com.br como fator para explicar as disfunções sociais e psicológicas encontrou seus limites com o TDAH. (p. 2)

A Gestalt-Terapia (GT) é uma abordagem fenomenológico-existencial com uma visão holística de doença. Compreende o adoecer como resultante de uma desarmonia relacional entre pessoa e ambiente que formam uma unidade dialética e indivisível. Ribeiro (1997) enuncia: "A doença é relacional. Não existe doença em si. Doença é fenômeno como processo; como dado, existe em alguém, e não como realidade em si mesma (...)" (p. 36).

O enfoque gestáltico, portanto, visa ir além da descrição dos sintomas que define uma doença, busca o sentido da patologia e as vivências subjetivas da pessoa adoecida. Sendo assim, o objetivo principal da pesquisa consistiu em investigar os processos psicológicos e relacionais da criança hiperativa, a partir da teoria do ciclo do contato da Abordagem da Gestalt, compreendendo que a hiperatividade e a desatenção constituem apenas uma parte de sua totalidade existencial.

Transtorno de Déficit de Atenção/Hiperatividade: uma breve revisão da literatura

Essa síndrome tem sido descrita extensivamente na literatura médica por longas décadas. Já recebeu diversas nomenclaturas e parte da sua controvérsia se deve a essas 
mudanças na terminologia, alterações que refletiram tendências históricas na conceitualização da etiologia e nos aspectos essenciais do transtorno.

A evolução histórica da terminologia inicia, em 1947, com Strauss e Lehtinen (conforme citado por Gorodscy, 1991) que utilizam a denominação Síndrome de Lesão Cerebral Mínima para classificar crianças com hiperatividade, "distratibilidade", distúrbios cognitivos e problemas de adaptação social. Em 1962, a hipótese de lesão cerebral é abandonada em razão da falta de comprovação neurológica, substituindo-se o termo para Disfunção Cerebral Mínima (DCM) que foi largamente aceito durante alguns anos.

A noção de que a atividade motora excessiva era a condição primária da desordem se tornou proeminente entre os anos de 1950 a 1970. O termo hipercinesia passa a ser empregado equivalendo a hiperatividade e alguns autores começam a estudar a hipercinesia, tanto de um ponto de vista sintomático, quanto em um sentido "sindrômico".

A compreensão desse quadro nosológico continuou insatisfatória e com pouca aceitação científica. A criação de uma classificação com maior validade e confiabilidade começou com a CID-9 (Organização Mundial de Saúde, 1965) e com o DSM-II (Associação Psiquiátrica Americana, 1968), quando a terminologia foi mudada para Síndrome Hipercinética da Infância.

Discussões sobre qual o elemento primário da patologia permaneceram. Em 1980, a Associação Psiquiátrica Americana (APA) cunhou a nomenclatura Síndrome de Déficit de Atenção com ou sem Hiperatividade relegando a hiperatividade a um segundo plano. O DSM-III-Revisado (APA, 1987), em seguida, modifica o termo para Distúrbio de Déficit de Atenção por Hiperatividade tornando novamente a inquietação o elemento essencial ao transtorno.

A partir de novos estudos que verificaram que tanto a falta de atenção quanto a hiperatividade estavam presentes, o DSM-IV (1994) apresenta a mais nova e atual denominação: Transtorno de Déficit de Atenção/Hiperatividade. Essa classificação reúne 18 sintomas de desatenção, hiperatividade e impulsividade e distingue três subtipos para fins de diagnóstico: o predominantemente desatento, o predominantemente hiperativo/impulsivo e o tipo combinado que reúne características dos dois anteriores.

As investigações científicas atuais para a determinação da etiologia da síndrome atingem um amplo campo que vai desde aspectos bioquímicos e neurológicos até psicológicos e sócio-ambientais.

Barbosa, Gaião e Di Lorenzo (1996) distinguem três concepções etiológicas para o TDAH: a) a que defende a síndrome como um transtorno de personalidade, oriunda das abordagens psicodinâmicas; b) a de base orgânica que considera o transtorno como sendo uma afecção cerebral; e c) a genética, com a idéia de uma possível transmissão genética nas bases do TDAH.

No campo biológico, o meio científico tem valorizado duas hipóteses neurológicas. Estudos recentes sobre síndromes localizadas sugerem que o TDAH resulta de uma disfunção do lobo frontal devido a uma perturbação dos processos inibitórios do córtex. Uma outra proposta de base neurológica dada por Kornetsky (conforme citado por Hallowell \& Ratey, 1994/1999) enfoca um desequilíbrio neuroquímico nos sistemas neurotransmissores da noradrenalina e da dopamina, os quais se encontram em níveis inferiores, sendo o TDAH provocado por uma baixa produção ou subutilização dessas substancias. A etiologia genética tem sido sustentada a partir de estudos de família com filhos adotivos e gêmeos que verificaram antecedentes de hiperatividade nos pais e falta de associação entre crianças adotadas e pais adotivos.

Nas pesquisas de caracterização sócio-emocional, o estilo de criação e as características de personalidade dos pais são considerados fatores que interferem no desenvolvimento e curso do transtorno. Ajuriaguerra e Marcelli (1984/1986) abordam a questão clínica da síndrome, considerando que o transtorno hipercinético pode ser um estado reacional a uma situação traumatizante ou ansiogênica que responde a uma angústia permanente. Para Hernandez (1989), existe uma hiperatividade de comportamento ou uma hiperatividade reativa gerada em ambiente onde há relacionamentos familiares insatisfatórios e falta de reciprocidade afetiva, sendo a criança objeto de permanente desvalorização e alvo de crítica.

Pesquisas mais recentes têm apontado para uma etiologia multidimensional diante da complexidade desse transtorno e da falta de evidências científicas sólidas que sustentem uma etiologia única e de base exclusivamente biológica. Estudiosos passaram a afirmar que a vulnerabilidade biológica e os fatores psicossociais interagem de um modo circular com relação à causa, gravidade e resultado do transtorno. Para Barkley, Murphy e Bauermeister (1998), o TDAH envolve interações multidirecionais, recíprocas e dinâmicas entre influências genéticas, neurais, psicológicas, comportamentais e ambientais que ocorrem ao longo do desenvolvimento da criança.

No Brasil, estudos epidemiológicos realizados com base nos critérios diagnósticos do DSM-IV, situam a prevalência do TDAH entre 3\% e 5\%. A síndrome é mais comum em meninos $(9 \%)$ com sintomas de hiperatividade do que em meninas (3\%) que apresentam mais sintomas de desatenção (Rohde, Barbosa, Tramontina \& Polanczyk, 2000).

As pesquisas mostram uma alta taxa de co-morbidade entre o TDAH e os transtornos disruptivos do comportamento (transtorno de conduta e transtorno desafiador de oposição); depressão; transtorno de ansiedade; e transtorno da aprendizagem. No entanto, não há estudos que expliquem as razões para que ocorram as co-morbidades. A escassa existência da sua condição "pura" revela a fragilidade de seu status de entidade nosológica diferenciada que nos alerta para a questão de que a essência do TDAH ainda não foi encontrada.

\section{Principais características e dificuldades básicas}

Atualmente, o Transtorno de Déficit de Atenção/ Hiperatividade é uma terminologia usada para descrever uma desordem específica do desenvolvimento exibido por crianças com deficiências em sustentar a atenção, inibir os impulsos e regular a atividade motora nas diversas situações de vida.

Para fins diagnósticos, o DSM-IV exige que os sintomas de falta de atenção, hiperatividade e impulsividade tenham surgido antes dos sete anos, que ocorram freqüentemente, que sejam mal-adaptativos e inconsistentes com o nível de desenvolvimento da criança, que persistam por, no mínimo, seis meses e se manifestem em dois ou mais ambientes. Pelo 
menos seis dos sintomas de desatenção e/ou seis dos sintomas de hiperatividade/impulsividade têm que estar presentes freqüentemente na vida da criança.

A fraca capacidade de manter a atenção focalizada, quando distintos estímulos no ambiente distraem com facilidade a criança, designa o tipo predominantemente desatento. A sua atenção difusa (dirige a atenção a muitas coisas ao mesmo tempo) cria problemas no pensamento e na memória. Essa criança, contudo, é capaz de se concentrar horas em uma atividade que aprecia e na qual é habilidosa. Uma explicação dada por Barkley e cols. (1998) para esta "desatenção seletiva" relaciona-se à motivação e ao prazer desencadeado pela tarefa, como se essa criança fosse movida por estímulos excitantes, onde o mundo tem que ser interessante e tudo aquilo que for aborrecido, tedioso, prolongado ou repetitivo não tem um atrativo intrínseco.

Segundo as leis da percepção, nem todo dado de realidade é objeto de percepção, ou seja, "nem tudo o que se olha é o que se vê". O ato de focalizar a atenção requer uma intencionalidade da consciência, onde a atenção voluntária impõe um esforço mental para orientar a atividade psíquica em direção a um estímulo e mantê-lo dentro do campo perceptivo consciente. Todo ato de percepção revela, portanto, um processo de "atenção seletiva" e/ou "desatenção seletiva".

A hiperatividade como característica marcante e atrelada à impulsividade distingue a criança por estar em constante movimentação corporal durante a execução de uma atividade e por agir impulsivamente ("sinto, logo ajo"). A criança responde aos múltiplos estímulos ambientais com uma prontidão imediata, parecendo não selecionar conscientemente a tarefa ou o objeto prioritário de sua ação. A inquietação revela uma falta de controle do próprio corpo, indicando uma desarmonia entre o sentir, o pensar e o agir.

A psicomotricidade ocupa-se do movimento humano como primeiro instrumento na construção do psiquismo e aponta com grande ênfase a ação recíproca entre movimento, emoção, indivíduo e meio ambiente. Sustenta que a atividade motora constrói a imagem corporal como resultado da ação dinâmica entre as experiências intracorporais e extracorporais, e que a imagem corporal dá a base para a criança agir no mundo de forma organizada e adaptada ao espaço envolvente.

Em uma nova ótica epistemológica, o olhar não está mais situado apenas no motor, num corpo instrumental, mas "num corpo em movimento que à medida que se desloca constrói a realidade e a própria capacidade intelectiva, que sente, que se emociona e cuja emoção manifesta-se tonicamente" (Levin, 1991/2001, p. 31). O corpo é construído e constituído a partir de uma história. Corpo, motricidade e emocionalidade formam uma unidade e uma totalidade.

Portanto, o que fala é o sujeito através do seu corpo, das variações tônico-motoras, do movimento, dos gestos e do esquema corporal que são representantes de uma organização psíquica. Este é o desafio que nos lança a criança hiperativa com o seu corpo em contínuo movimento.

\section{A abordagem da Gestalt: uma visão geral}

Gestalt é uma palavra alemã que significa forma, configuração, todo significativo, entidade estrutural. Ao ser apropriada pela Psicologia da Gestalt, passa a representar uma unidade perceptiva cujo sentido é dado pelas inter-relações específicas entre as partes, aquilo que faz do todo uma unidade diferente da simples soma das partes.

A história da Gestalt-Terapia (GT) tem sua origem com Fritz Perls (1893-1970) que, em colaboração com Laura Perls, Paul Goodman e Ralph Hefferline, fundou uma abordagem de base holística-existencial-fenomenológica reunindo elementos da Teoria do Campo, da Teoria Organísmica, da Psicologia da Gestalt e das concepções filosóficas do Humanismo, Existencialismo e da Fenomenologia.

Sustentada em suas teorias de base, a GT formula que o campo organismo/ambiente constitui uma unidade inseparável, uma totalidade cujo significado emerge das inter e intra-relações entre as partes que formam um dado todo. Dessa totalidade, figuras emergem em relação a um fundo, e essa relação entre figura e fundo funciona dinamicamente e dá significado aos fenômenos. Uma boa gestalt é clara e a relação figuralfundo reage a padrões mutantes das necessidades imediatas da pessoa. Necessidades não atendidas formam gestalten incompletas, exigindo atenção e interferindo na formação de novas gestalten (Yontef, 1993/1998, p. 213). Para o gestaltista, a experiência segue um fluxo natural de surgimento e mudança de figuras, na qual o comportamento pode variar conforme as condições ambientais e as necessidades da pessoa.

Em Gestalt, contato e awareness ${ }^{3}$ formam o eixo básico para a compreensão da forma de pensar, agir e sentir da pessoa. Awareness dá o significado e sentido da experiência, formando gestalten. Contato é o processo psíquico ou comportamental pelo qual o indivíduo entra em relação consigo, com o outro e com o mundo em busca da diferenciação. Perls, Hefferline e Goodman (1951/1997), na obra clássica Gestalt Therapy, definem de maneira sucinta a dinâmica do contato de união/separação, evitação/aproximação, identificação/alienação: Primordialmente, contato é a awareness da novidade assimilável e comportamento com relação a esta; e rejeição da novidade inassimilável. O que é difuso, sempre o mesmo, ou indiferente, não é objeto de contato (p. 44). Portanto, contato representa um processo ativo e consciente de ajustamento criativo e enfatiza o princípio ontológico existencial que concebe o indivíduo como ser relacional.

Os movimentos dialéticos representativos da experiência do contato ocorrem por meio da auto-regulação organísmica realizada pelo self no campo organismo/ambiente. Esse processo revela um fluxo dinâmico de ciclos sucessivos de satisfação de necessidades, onde uma figura emerge de um fundo indiferenciado. A interrupção sistemática e repetida do fluxo de formação e dissolução de figuras deixa gestalten abertas e necessidades não satisfeitas. Cada situação incompleta retém energia mental e física em torno de uma necessidade insatisfeita que exerce permanente pressão psíquica para sua realização e, assim, leva a pessoa a manter comportamentos repetitivos e obsoletos em sua vida presente. Para a GT, doença significa perturbação no processo de

3 O termo awareness é mantido originalmente em inglês por apresentar um sentido mais amplo que o termo consciência. Representa a consciência que apreende a totalidade dos fatos, o ato de ter consciência da própria consciência. 
formação-destruição-reforma de gestalten (Clarkson, 1989) que interrompe o fluxo natural da experiência. Representa a incapacidade de uma pessoa em reconhecer a necessidade dominante, de discriminar o objeto que irá satisfazer sua necessidade, de permanecer em contato com esse objeto e de se retrair após o fechamento de uma gestalt.

\section{Campo holístico relacional}

Ribeiro (1997) sustentado na Teoria do Campo e na Teoria Organísmica-Holística cria o modelo Campo Holístico Relacional (Figura 1), o qual anuncia que a pessoa é um campo e é de um campo (grifo nosso). Esse modelo possibilita uma visão macro e microsistêmica dos diversos campos que compõem a realidade existencial do indivíduo (campo geobiológico, campo sócio-ambiental, campo psico-emocional e campo sacro-transcendental) e concebe a inter e intra-relação entre os campos, no qual nada que ocorra em um campo é neutro para um outro e para o todo holístico relacional.

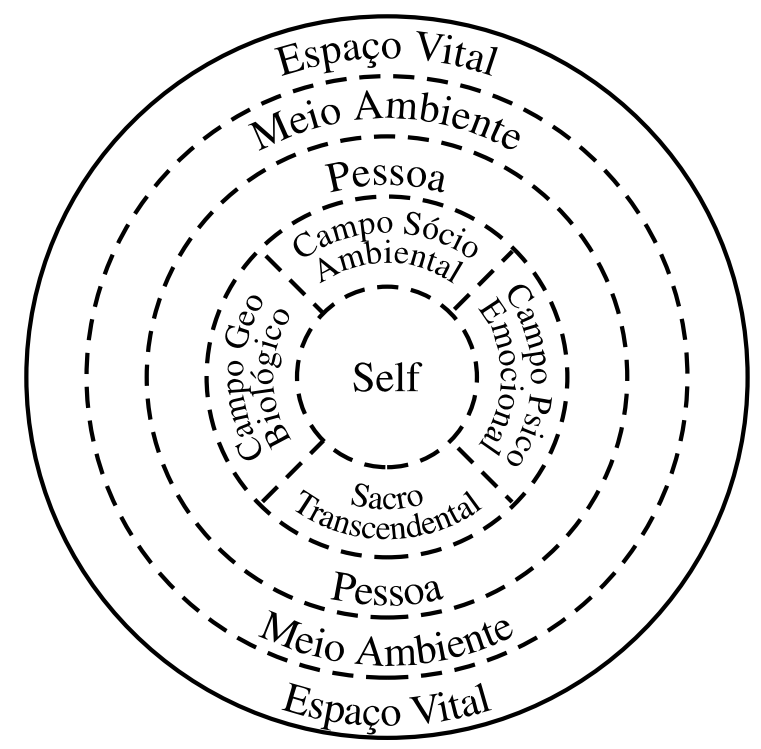

Figura 1. Campo holístico relacional Fonte: Ribeiro (1997)

O indivíduo é formado pelos sistemas sensorial-motorcognitivo, os quais ora se relacionam mais com um determinado campo, ora mais com outro, podendo criar múltiplas possibilidades de formas de contato e de comportamento. $\mathrm{O}$ autor exemplifica hipoteticamente a dinâmica do funcionamento psicológico de uma criança, demonstrando como cada sistema se conecta com um dado campo, criando um padrão de contato com o mundo:

A criança que tem seu sistema motor inibido com "não faça isto, não faça aquilo"; seu sistema cognitivo superestimulado com "pense sempre antes de agir, cuidado com erros", terá estes dois tipos de introjetos afetando imediatamente seu campo psicoemocional, produzindo nela um medo generalizado e sentimentos de insegurança que afetam seu campo sócio-ambiental, fazendo-a assumir sempre atitudes tímidas, prudentes, com dificuldades de relacionamento e profunda desconfiança de si mesmo. (Ribeiro, 1997, p. 24)
Assim, cada indivíduo pode apresentar comportamentos diferentes em ambientes diferentes. O campo cria necessidades e comportamentos diferentes, assim como a necessidade organiza o comportamento e o campo. Compreende-se, portanto, a razão da criança hiperativa variar o seu comportamento irrequieto em distintos contextos de vida.

\section{Ciclo do contato}

Perls e cols. (1951/1997), inicialmente, descreveram o processo do contato como um todo unificado, representado em uma sequiência contínua de figura-fundo, que tem origem numa vaga sensação que se delineia como figura, levando à mobilização de energia e a uma ação organizada que responde a uma necessidade emergente. $\mathrm{O}$ ciclo se fecha quando o organismo tem a experiência de satisfação plena, entrando em retraimento e colocando-se, em seguida, à disposição de uma nova figura. Para os autores, em todo processo de contato há uma unidade subjacente de funções perceptivas, motoras e sensório-afetivas que funcionam de modo integrado. A experiência do contato foi definida como um excitamento crescente consciente que ocorre em quatro estágios:

1) Pré-contato: o corpo é o fundo e o estímulo ambiental ou a excitação organísmica é a figura.

2) Contato: a) o excitamento no corpo torna-se o fundo e algum objeto ou conjunto de possibilidades é a figura; b) há a escolha e a rejeição de possibilidades, ocorrendo as identificações e alienações de objetos e experiências.

3) Contato final: o ambiente e o corpo são o fundo e o objetivo vívido é a figura; há uma ação espontânea unitária da percepção, do movimento e do sentimento; o self está plenamente aware da figura que descobriu e inventou.

4) Pós-contato: há uma interação fluida entre organismo/ambiente e não há uma diferenciação figura/fundo, mas uma unidade figura/fundo; o self se retrai em uma sensação de completude.

De acordo com a teoria da Gestalt, os bloqueios do contato são mecanismos psicológicos que exercem funções defensivas e constituem padrões de comportamento e percepção pelos quais o indivíduo mantém, no presente, situações mal resolvidas do passado, impedindo-se de realizar um contato saudável. Segundo Clarkson (1989) e Ribeiro (1997) cada indivíduo pode interromper o ciclo em qualquer ponto, conforme as exigências do contexto, porém existe um lugar onde o bloqueio é mais constante e define a sua dinâmica intra e interpessoal. É válido ressaltar que esses processos do contato possuem uma função saudável quando empregados flexivelmente, atendendo às condições da situação e às necessidades originais do indivíduo.

O modelo adotado neste trabalho que retrata o ciclo da experiência do contato é de autoria de Ribeiro (1997), nomeado de Ciclo dos Fatores de Cura e Bloqueios do Contato (Figura 2) que reconhece nove fases do contato (fluidez, sensação, consciência, mobilização, ação, interação, contato final, satisfação e retirada) e nove mecanismos de bloqueio do contato (fixação, dessensibilização, deflexão, introjeção, projeção, proflexão, retroflexão, egotismo e confluência) como formas polares complementares, mostrando a dinâmica entre saúde e doença. Este modelo condensa uma visão mais 
abrangente e atualizada do fluxo dinâmico da experiência humana na abordagem gestáltica.

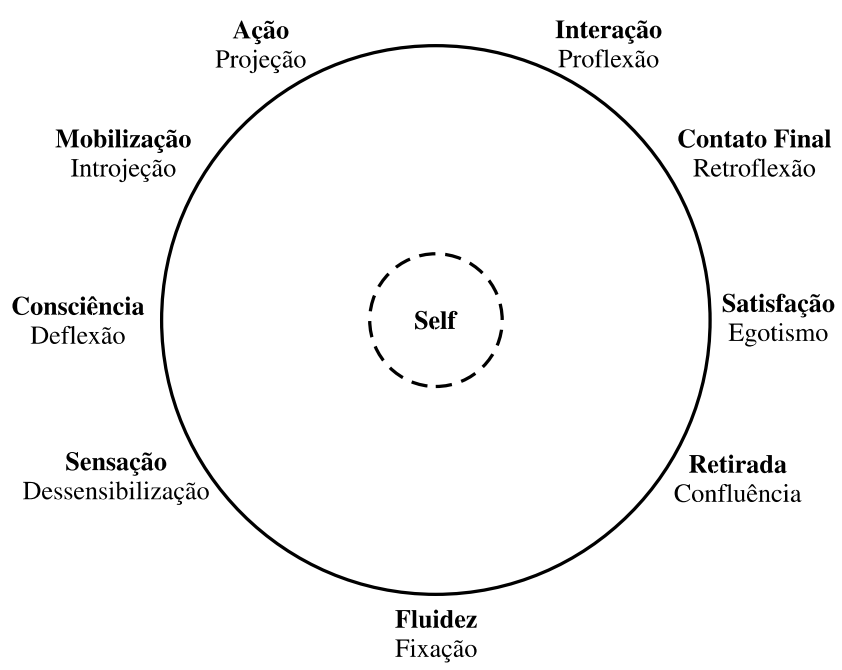

Figura 2. Ciclo dos fatores de cura e bloqueios do contato Fonte: Ribeiro (1997)

A partir da visão holística da GT, acreditamos que é imprescindível se tomar em consideração a influência do ambiente social e familiar, caso se deseje compreender plenamente essa síndrome, diagnosticá-la com acerto e prover os tratamentos necessários. Sendo assim, o objetivo geral do trabalho é compreender o funcionamento psicológico da criança hiperativa com base na Teoria do Ciclo do Contato da abordagem gestáltica, de forma a identificar os fatores de cura e os bloqueios do contato utilizados por essa criança. Como objetivo específico, pretendemos oferecer uma contribuição psicopedagógica para abordar a criança hiperativa, a partir de um modelo de intervenção de base gestáltica.

\section{Metodologia}

Pelo fato desse trabalho ter se originado em um contexto clínico terapêutico voltado para compreender os processos psicológicos que regem o comportamento da criança hiperativa, essa pesquisa seguiu uma metodologia de natureza qualitativa de base fenomenológica cuja essência é a descrição da realidade observada e experienciada.

Segundo Martins e Bicudo (1988), a pesquisa baseada na abordagem qualitativa busca uma compreensão particular daquilo que se estuda e não a explicação dos fenômenos estudados. Neste sentido, Quinn Patton (conforme citado por González- Rey, 1999, escreve: “Os métodos qualitativos são particularmente orientados para a exploração, o descobrimento e a lógica indutiva. Um enfoque avaliativo é indutivo quando o investigador intenciona criar sentido da situação, sem impor expectativas preexistentes sobre o fenômeno ou situação estudada" (p. 131).

\section{Universo da pesquisa}

O universo da pesquisa compõe-se de 20 pessoas, sendo elas: cinco crianças (quatro meninos e uma menina cujos nomes são fictícios) na faixa etária de 8 a 11 anos, selecio- nadas no Centro de Orientação Médico-Psicopedagógica (COMPP), Unidade da Secretaria de Estado de Saúde do Distrito Federal - SES/DF, com diagnóstico psiquiátrico de Transtorno de Déficit de Atenção/Hiperatividade; cinco casais; e cinco professoras.

Foram escolhidas crianças diagnosticadas com o TDAH "puro", não associado a outras co-morbidades (Transtorno de Conduta, Transtorno Desafiador de Oposição, Transtorno de Ansiedade, Depressão, Deficiência Mental e Epilepsia) e que não estivessem em uso de medicação.

\section{Instrumentos e procedimentos}

Foram utilizados dois instrumentos para coleta de dados: a entrevista aberta com os casais e as professoras; e o Teste de Apercepção Infantil com figuras de animais (CAT-A) aplicado às crianças. Foram realizadas dez entrevistas abertas. Todas as entrevistas e testes foram gravados e transcritos.

As entrevistas com os pais foram realizadas separadamente, em sala reservada, no COMPP, empregando-se a questão orientadora: "Como vocês percebem seu filho?" As entrevistas com as professoras foram feitas na própria escola em que lecionam e iniciou-se com a seguinte pergunta: "Como você percebe essa criança em sala de aula?" Perguntas complementares foram feitas visando obter o máximo de informações sobre o modo de sentir, pensar, agir e interagir dos sujeitos.

O método projetivo infantil (CAT-A) foi aplicado pela própria pesquisadora e a análise interpretativa das estórias narradas foi feita por uma psicóloga clínica com formação em Gestalt-Terapia que trabalha no setor de psicodiagnóstico do COMPP.

\section{Análise dos dados}

A análise dos dados das entrevistas com os pais e professoras foi feita com base na técnica de análise de conteúdo do tipo categorial proposta por Lawrence Bardin. A análise dos dados das crianças foi realizada mediante a análise interpretativa do CAT- A, as observações comportamentais durante as sessões de aplicação e os dados de anamnese obtidos dos prontuários das crianças.

Para discussão dos resultados, foram organizados quadros referentes às categorias levantadas para cada professora e cada casal com as respectivas frequiências de verbalizações; quadros relacionados às categorias levantadas para os dois grupos de sujeitos compostos por definição da categoria, temas representativos e exemplos de verbalizações; e um quadro geral dos processos básicos de contato utilizado pelas crianças. Apresentaremos o quadro geral das categorias-sínteses com suas respectivas freqüências (Tabela 1) e o quadro geral dos processos básicos do bloqueio do contato (Quadro 1) para fins ilustrativos e discussão dos resultados.

\section{Resultados e Discussão}

Serão discutidas aquelas categorias que apresentaram maior freqüência e que tiveram relevância para elucidar os processos psicológicos e relacionais das crianças. Iniciaremos analisando os aspectos cognitivos. 
Tabela 1. Freqüência das categorias-sínteses das professoras e dos casais

\begin{tabular}{lclc}
\hline \multicolumn{2}{c}{ Professoras } & \multicolumn{2}{c}{ Casais } \\
\hline \multicolumn{1}{c}{ Categorias } & Freqüência & \multicolumn{1}{c}{ Categorias } & Freqüência \\
\hline $\begin{array}{l}\text { Desempenho } \\
\text { Escolar }\end{array}$ & 49 & Afetividade & 48 \\
$\begin{array}{l}\text { Características da } \\
\text { Criança }\end{array}$ & 40 & Inquietação & 42 \\
$\begin{array}{l}\text { Relação com os } \\
\text { Colegas }\end{array}$ & 30 & Determinação & 40 \\
Inquietação & & & \\
Relação com a & 21 & Relação Familiar & 34 \\
Professora & 28 & Sentimentos dos & 28 \\
Sentimentos da & 18 & Pais & Características dos \\
Professora & & Pais & 20 \\
Desatenção & 15 & Conflitos Familiares & 17 \\
Afetividade & 14 & Relação com os Pais & 15 \\
Ansiedade & 13 & Desatenção & 11 \\
Agressividade & 10 & Relação com o & 10 \\
& & Irmão & \\
& & Desempenho & 09 \\
& & Escolar & \\
\hline
\end{tabular}

Legenda: As categorias foram extraídas da análise de conteúdo das entrevistas abertas realizadas com os pais e as professoras.

A categoria Desempenho Escolar aponta particularidades no funcionamento cognitivo das crianças, inter-relacionando atenção-pensamento-memória. Com exceção de Artur (que possui nível intelectual acima da média), todas as demais crianças apresentam atraso no processo de aprendizagem com deficiências específicas na leitura e na escrita. A letra é irregular, sem padrão e a leitura não segue uma seqüência ("pula frases"), o que indica deficiências no funcionamento viso-motor.

Problemas no processo de organização e execução do pensamento foram descritos. Surge o $1^{\circ}$ paradoxo dentro do Transtorno: Lentidão no pensamento x Rapidez na percepção. Deduzimos que essa lentidão (considerada como "preguiça mental" pelos pais e professoras) seja resultado da percepção rápida e do fluxo contínuo de idéias que a criança precisa regular a fim de organizar seus pensamentos de forma significativa e coerente para, então, interpretar e escrever aquilo que compreendeu.

Essa dificuldade no processamento das informações impede a criança de acompanhar o ritmo e a demanda escolar. Passa, então, a agir com desinteresse nos estudos com condutas de fuga cujo intuito é desviar o contato com o sentimento de incompetência cognitiva gerador de ansiedade, por não dar conta de responder as exigências escolares.

A categoria Desatenção apresentou uma freqüência muito baixa, mas foi mantida na tabela das categorias-sínteses para fins de discussão clínica. As professoras e os pais falam que a criança presta atenção em tudo e em todos, mas parece não escutar ou "estar voando" quando o assunto é de natureza acadêmica ou quando são repreensões. Surge o $2^{\circ}$ paradoxo: Atenção x Desatenção.

A criança orienta e sustenta a atenção quando algo é de seu interesse, fazendo uso das funções da atenção de selecionar, focar, manter e dividir. Há um fenômeno motivacional ocorrendo subjacente ao fenômeno cognitivo da atenção, a qual flutua para situações que tem valência positiva fugindo daquelas com carga negativa, logo existe uma "atenção seletiva" e uma "desatenção seletiva". A criança, portanto, desvia a atenção de tudo aquilo que fere sua auto-estima e senso de competência.

O esquecimento considerado uma manifestação da Desatenção é visto como uma falha de memória pelos pais e professoras. A criança possui boa memória para certas coisas e até para conteúdos disciplinares, no entanto, esquece logo o que the foi ensinado ou de dar recados. Se a criança tem dificuldades no processamento de informações e na organização do pensamento, ela terá problemas na memória de associação (ou sequiencial) e na retenção de informações complexas. A memória "boa", portanto, é a memória relacionada ao armazenamento de dados simples, a coisas que não exigem esforço mental de elaboração.

Compreendemos que essa criança, na verdade, não tem um déficit de atenção, mas uma hiperatenção, uma imensa capacidade de atentar para os múltiplos estímulos ambientais. Há uma atenção exagerada voltada para o ambiente, onde a percepção contínua do externo sobrepõe-se à percepção do próprio self, evidenciando uma reduzida consciência de suas experiências internas. A criança é fundo, o ambiente é figura. A atenção é difusa porque a consciência é confusa. Não sabe o quê procura e para quê, mantendo um contato superficial consigo e com o mundo.

A inquietação é unânime para pais e professoras como característica prevalente e padrão anormal de comportamento. Um menino comenta no CAT-A que "o macaco nasceu com problema de chatice". Um outro se identifica com o cachorro e diz: "Ele tem um negócio no corpo, tem um tipo de deficiência moral, moral. Aí, ele não consegue pensar com essa doença". As crianças reconhecem o seu problema comportamental e sentem a hiperatividade/impulsividade como uma dificuldade em controlar o corpo e o pensamento.

A discussão anterior a respeito das características comportamentais e cognitivas da criança coloca a Deflexão ${ }^{4}$ como o processo psicológico que define a patologia. Iremos elucidar, agora, como o TDAH se mostra na dimensão intrapsíquica da criança.

Quadro 1. Quadro geral dos processos básicos de bloqueio do contato das crianças

\begin{tabular}{cl}
\hline Crianças & \multicolumn{1}{c}{ Processos do Contato } \\
\hline João & Projeção, Egotismo, Deflexão \\
Pedro & Projeção, Egotismo, Deflexão \\
Artur & Projeção, Egotismo, Deflexão \\
Marco & Egotismo, Deflexão \\
Lia & Introjeção, Retroflexão, Deflexão \\
\hline
\end{tabular}

Legenda: Os processos de bloqueio do contato foram obtidos das entrevistas abertas realizadas com os pais e as professoras e da análise do CAT-A.

A Afetividade e a Determinação como categorias destacadas da análise de conteúdo conferem grande importância ao campo psicoemocional da criança hiperativa. A Afetividade revela uma intensa sensibilidade e reatividade emocional e um modo generoso de ser com o outro. Na compreensão

4 Deflexão é o processo de evitação do contato por meio da atenuação ou desvio da ação ou atenção de um objeto provocador de ansiedade, ocasionando um modo vago, indireto e superficial de interagir. 
dos pais e professoras, são crianças com uma alta demanda de afeto que possuem uma carência afetiva, ou melhor, um Déficit de Afetividade. Surge o $3^{\circ}$. paradoxo: Déficit de Afetividade $x$ Hiperemotividade. Os dois extremos experimentados pela criança revelam uma dialética paradoxal de fenômenos que regulam o equilíbrio do organismo: Hiper $\mathrm{x}$ Déficit. Esse funcionamento desarmonioso mostra que "o excesso cria a falta", uma deficiência em uma função oposta complementar.

A Determinação descreve a persistência da criança com aquilo que quer, seu modo voluntarioso e imperativo de agir. Não aceita opiniões ou imposições e quer fazer as coisas do seu jeito mesmo que seja errado. Essa categoria retrata as características de onipotência e auto-referência da criança que suscitam problemas na interação com o outro. Esse funcionamento centrado em si mesmo, com uma preocupação voltada para as próprias necessidades e identidade, representa a dinâmica do Egotismo.

As estórias narradas pelas crianças no CAT-A revelam intensos sentimentos de inadequação, incompreensão e rejeição. Percebem o ambiente como punitivo e intolerante, embora se considerem merecedoras de punição. No entanto, reagem às constantes críticas numa tentativa de recusar o juízo depreciativo alheio. A hiperatividade, enquanto conduta desorganizada, representa assim a Projeção ${ }^{5}$ de introjetos negativos oriundos do meio do qual tem que se defender, do tipo: "Você é chato. Você é desobediente. Você está sempre aprontando, fazendo coisas erradas". A criança vive um conflito interno entre os "não deverias" e aquilo que é originalmente seu modo de ser e agir, como se não pudesse aceitar os próprios sentimentos, pensamentos e ações. Por conseguinte, a criança cria um senso de self negativo oriundo de uma confusa imagem corporal. A hiperatividade ainda pode expressar uma forma de recusar o pensar as ações desamorosas e intolerantes vindas do ambiente, representando um estado permanente de tensão e ansiedade vivido pela criança.

Em conclusão, os processos de bloqueio do contato básicos que organizam o funcionamento psicológico das crianças da pesquisa são: Deflexão, Projeção e Egotismo. A combinação dinâmica desses três mecanismos revela os seguintes processos internos e relacionais da criança: a criança deflete por meio da inquietação e da desatenção. Ao defletir com uma ação motora excessiva que ocorre em simultaneidade com a atenção difusa, a criança passa a se comportar de forma inapropriada sem atender a necessidade prioritária. Sua ação desorganizada advém da Projeção ao lançar no ambiente partes de si consideradas inaceitáveis (introjetos tóxicos) que, por sua vez, cria perturbação na qualidade da interação. Nesse ponto, a criança recorre à Proplexão ${ }^{6}$ como mecanismo saudável para reparar as suas condutas inadequadas, sendo prestativa na esperança de receber em troca aprovação e afeto

5 Projeção é o processo pelo qual a pessoa atribui aos outros sentimentos, pensamentos e comportamentos intoleráveis da expressão de si mesma, desapropriando-se das partes de si em que surgem as excitações e impulsos.

6 Proflexão é o processo pelo qual a pessoa faz ao outro aquilo que gostaria que fizessem com e para ela numa tentativa de conseguir que o outro preencha as suas necessidades. para compensar seu Déficit de Afetividade. O Egotismo revela a luta da criança (por meio da determinação) para impor sua identidade e modo de ser perante o mundo. Assim, seu modo de agir, pensar e sentir reflete: "Já que o mundo não me aceita como eu sou, não me compreende e não atende as minhas necessidades de afeto, eu mesma vou me nutrir, vou fazer o que eu quero. Ninguém manda em mim".

A menina Lia apresentou uma inquietação reduzida, tendo a desatenção como característica predominante. Revelou dois mecanismos do contato distintos dos meninos (introjeção, retroflexão), configurando um funcionamento psicológico diferente.

Analisando a criança hiperativa do ponto de vista dos fatores de cura do ciclo do contato, temos: a inquietação e a desatenção significam que a criança está em permanente processo de fluidez, em contínuo movimento em busca de novos estímulos. Há um excesso de excitação que cria um alto nível de mobilização de energia para a execução da ação, a qual é efetuada pronta e impulsivamente. Mantém um contato superficial com as coisas, trocando incessantemente o foco da atenção de um objeto a outro, prematuramente, sem manter a continuidade até o fechamento da gestalt. A criança não se satisfaz totalmente, não alcança a harmonia organísmica, experienciando um estado permanente de insatisfação. A criança, portanto, vive um processo interminável de busca da própria auto-regulação, no qual a hiperatividade e a desatenção disfarçam a condição essencial da síndrome que reflete uma busca alienada de objetivos e sentido da existência.

Uma vez que a desatenção acompanha o fluxo da excitação, não se deveria diagnosticar hiperatividade sem sintomas de desatenção, ou seja, DDA sem hiperatividade, como indicado no DSM-IV. Caso existam apenas sintomas de desatenção deve se reconhecer uma categoria nosológica diferenciada. Face às reflexões apresentadas, propomos seja pensada uma diferente terminologia: Transtorno de Hiperatividade/Atenção.

\section{Conclusão}

O TDAH representa um alto nível de excitação organísmica com implicações orgânico-funcionais associadas a fenômenos de ordem emocional. O elevado fluxo de energia faz a criança funcionar em "alta voltagem" respondendo ao mundo com Hiperatividade, Hiperatenção e Hiperemotividade, como uma totalidade em ação. O TDAH é colocado totalmente no domínio da patologia, o que não é correto. Há talentos oriundos dessa alta excitabilidade - a intuição, a criatividade, a afetuosidade, a vitalidade - que devem ser sobrepostos aos supostos déficits.

Essa criança lança um desafio aos educadores, aos pais, aos profissionais da saúde para uma mudança em seus modelos de pensamento, de intervenção, de interação. Ela não aceita ser vítima de métodos padronizados de ensino ou modelos educacionais rígidos. Anseia por criatividade, flexibilidade, afetividade e, sobretudo, ser tratada como sujeito responsável por seu processo de aprendizagem.

Em nossa pesquisa, foi possível oferecer um número amplo de propostas psicopedagógicas para abordar a criança no campo acadêmico visando favorecer o seu desempenho escolar. Destacamos as mais importantes, a seguir: 
- Dar informações, instruções/orientações curtas e breves.

- Repetir as informações e fazer a criança repetir o que lhe foi dito ou ensinado.

- Exigir uma quantidade menor de tarefas e questões nas avaliações.

- Realizar mais avaliações orais do que escrita.

- Exercitar as habilidades motoras finas relacionadas à percepção visual.

- Trabalhar positivamente o olhar e o ouvir aguçados da criança com exercícios de seleção e focalização de objetos-figuras.

- Interessar-se mais pelas coisas que a criança sabe fazer, por seus talentos e não somente pelas suas deficiências. Enfatizar mais as qualidades do que os supostos déficits.

- Aproveitar a alegria, vitalidade, criatividade, intuição, generosidade e afetuosidade da criança de forma a criar um ambiente positivo para possibilitar um contato saudável entre a criança e os colegas.

O caminho da saúde é o resgate da consciência sobre o seu corpo, pensamentos e sentimentos, de forma a tornar-se uma presença consciente. Aprender a assumir responsabilidade sobre suas ações e escolhas. Ser capaz de criar metas e reconhecer limites para dar sentido a sua existência. Exercer a auto-regulação de forma consciente para poder hierarquizar as suas necessidades e se ajustar criativamente ao meio.

O TDAH vem anunciar a totalidade da condição humana que está inserida em uma totalidade mais ampla que forma a realidade holística relacional. O TDAH está nas crianças assim como está no mundo com seu ritmo acelerado, retratando a desatenção humana e a inquietação ansiosa presentes na sociedade moderna. $\mathrm{O}$ todo está nas partes e a parte está no todo. Somos a sociedade que produzimos e que nos produz.

\section{Referências}

Ajuriaguerra, J. \& Marcelli, D. (1986). Manual de psicopatologia infantil. (A. E. Filman, Trad.) Porto Alegre: Artes Médicas. (Trabalho original publicado em 1984)

American Psychiatric Association (1989). DSM-IV, Manual diagnóstico e estatístico de distúrbios mentais. ( $3^{\mathrm{a}}$ ed.). São Paulo: Manole.

American Psychiatric Association (2000). DSM-IV, Manual diagnóstico e estatístico de transtornos mentais. ( $4^{\mathrm{a}} \mathrm{ed}$.). Porto Alegre: Artes Médicas Sul.

American Psychiatric Association (1987). DSM-III-R, Manual diagnóstico e estatístico de transtornos mentais ( $3^{\mathrm{a}} \mathrm{ed}$.). Porto Alegre: Artes Médicas Sul.
Barbosa, G. A., Gaião, A. \& Di Lorenzo, W. F. (1996). Transtornos hipercinéticos: Uma revisão crítica. Neurobiologia, 59(4), 125-136.

Barkley, R., Murphy, K. \& Bauermeister, J. (1998). Trastorno por déficit de atención e hiperatividad. New York: Guilford Press.

Clarkson, P. (1989). Gestalt counselling in action. London: Sage.

Debroitner, R. \& Hart, A. (1997). Moving beyond ADD/ADHD - The book. Retirado em 07.02.2001, http://www.magicnet. net/ joeg/beyond/book.html

Gorodscy, R. (1991). A criança hiperativa e seu corpo: Um estudo compreensivo da hiperatividade em crianças. Tese de doutorado, Universidade de São Paulo, São Paulo.

Hallowell, E. \& Ratey, J. (1999). Tendência à distração: Identificação e gerência do distúrbio do déficit de atenção da infância à vida adulta. (A. Carvalho, Trad.) Rio de Janeiro: Rocco. (Trabalho original publicado em 1994)

Hernandez, M. (1989). Evaluación del niño hipercinético. Anales Español de Pedriatria, 1, 40-41.

Levin, E. (2001). A clínica psicomotora: O corpo na linguagem. (J. Jerusalinsky, Trad.) Petrópolis: Vozes. (Trabalho original publicado em 1991)

Martins, J. \& Bicudo, M. A. V. (1988). A pesquisa qualitativa em psicologia: Fundamentos e recursos básicos. São Paulo: Moraes.

Organização Mundial de Saúde (1993). Classificação de transtornos mentais e de comportamento da CID-10: Descrições clínicas e diretrizes diagnósticas. Porto Alegre: Artes Médicas.

Perls, F., Hefferline, R. \& Goodman, P. (1997). Gestalt-Terapia. (F. R. Ribeiro, Trad.) São Paulo: Summus. (Originalmente publicado em 1951).

Gonzalez- Rey, F. (1999). La investigación cualitativa en psicologia: Rumbos y desafíos. São Paulo: Educ.

Ribeiro, J. P. (1997). O ciclo do contato. São Paulo: Summus.

Rohde, L. A., Barbosa, G., Tramontina, S. \& Polanczyk, G. (2000). Transtorno de déficit de atenção/hiperatividade. Revista Brasileira de Psiquiatria, 22(2), 1-16.

Yontef, G. (1998). Processo, diálogo e awareness: Ensaios em Gestalt-Terapia. (E. Stern, Trad.) São Paulo: Summus. (Trabalho original publicado em 1993)

Recebido em 08.07.2003

Primeira decisão editorial em 15.04.2004

Versão final em 10.05.2004

Aceito em 30.06.2004 